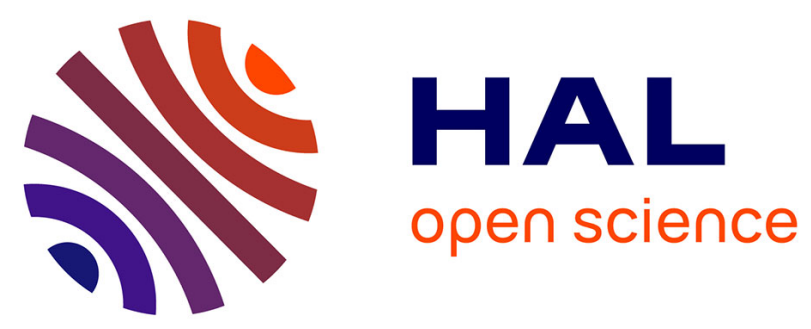

\title{
State observers for discrete-time LPV systems: an interpolation based approach
}

\author{
Jamal Daafouz, Iula Bara, Frédéric Kratz, José Ragot
}

\section{To cite this version:}

Jamal Daafouz, Iula Bara, Frédéric Kratz, José Ragot. State observers for discrete-time LPV systems: an interpolation based approach. 39th IEEE Conference on Decision and Control, CDC 2000, Dec 2000, Sydney, Australia. pp.4571-4572, 10.1109/CDC.2001.914635 . hal-00529075

\section{HAL Id: hal-00529075 \\ https://hal.science/hal-00529075}

Submitted on 5 Apr 2014

HAL is a multi-disciplinary open access archive for the deposit and dissemination of scientific research documents, whether they are published or not. The documents may come from teaching and research institutions in France or abroad, or from public or private research centers.
L'archive ouverte pluridisciplinaire HAL, est destinée au dépôt et à la diffusion de documents scientifiques de niveau recherche, publiés ou non, émanant des établissements d'enseignement et de recherche français ou étrangers, des laboratoires publics ou privés. 


\title{
STATE OBSERVERS FOR DISCRETE-TIME LPV SYSTEMS: An Interpolation Based Approach
}

\author{
Jamal Daafouz, G.Iuliana Bara, Frédéric Kratz and José Ragot \\ Centre de Recherche en Automatique de Nancy UPRES A 7039 \\ INPL-ENSEM, 2 Avenue de la forêt de Haye, \\ 54516 Vandœuvre Cedex, France \\ jdaafouz,ibara,fkratz,jragot@ensem.inpl-nancy.fr
}

\begin{abstract}
This paper invistigates a state observation design problem for discrete time linear parameter varying (LPV) systems. The main contribution of this paper consists in providing an interpolation scheme to build the LPV observer. We show that an appropriate choice of the interpolation functions allow to use available quadratic stability conditions to design an LPV observer.
\end{abstract}

\section{Introduction}

Linear Parameter Varying systems theory has been motivated by the gain scheduling approach which attempts to provide a systematic methodology to design parameter-dependent control laws that guarantee stability and performances specifications, see [1] and referenes therein. In this paper, we propose a parameter varying observer design procedure for discrete time linear parameter varying systems. In [2], interpolation based observers for continuous time LPV systems are proposed.

The paper is organized as follows. Section 2 gives the problem statement. Section 3 develops a solution for the interpolation based LPV observation problem. The choosen interpolation procedure is explained and justified. Conditions allowing the design of the parameter varying observer are given in terms of LMI conditions.

\section{Problem Formulation}

We consider LPV systems given by:

$$
\begin{aligned}
x(k+1) & =A(\rho(k)) x(k)+B u(k) \\
y(k) & =C x(k)
\end{aligned}
$$

where $x(k) \in \mathbb{R}^{n}$ is the state, $u(k) \in \mathbb{R}^{m}$ is the control and $y(k) \in \mathbb{R}^{p}$ is the measured output vector. The dynamical matrix depends on a time varying parameter $\rho(k) \in \Gamma \subset \mathbb{R}^{l}$ (possibly a vector). We assume that each parameter $\rho_{i}$ evolves in a bounded interval $\rho_{i}(k) \in$ $\left[\underline{\rho}_{i}, \bar{\rho}_{i}\right]$. The parameter vector $\rho(k)$ evolves in a bounded domain $\mathrm{D}$ called the parameter box of which $2^{l}$ vertices are defined by:

$$
\mathcal{V}_{D}=\left\{\left(w_{1}, w_{2}, \ldots, w_{l}\right) \text { such that } w_{i} \in\left\{\underline{\rho}_{i}, \bar{\rho}_{i}\right\}\right\}
$$

so that the LPV system is described by:

$$
A(\rho)=\sum_{i=1}^{2^{l}} \lambda_{i}(\rho) A_{i}, \lambda_{i}(\rho) \geq 0, \sum_{i=1}^{2^{l}} \lambda_{i}(\rho)=1
$$

where $A_{i}, i=1, \ldots, 2^{l}$, are constant matrices corresponding to $A(\rho(k))$ with $\rho(k) \in \mathcal{V}_{D}$. We look for a parameter varying observer with the following structure

$$
\begin{aligned}
\hat{x}(k+1)= & A(\rho(k)) \hat{x}+B u \\
& +L(\rho(k))(y(k)-\hat{y}(k)) \\
\hat{y}(k)= & C x(k)
\end{aligned}
$$

The parameter varying gain matrix $L(\rho(k))$ is obtained by interpolation of an off-line computed constant gains, namely those corresponding to the observers estimating the state of the original system when $\rho(k) \in \mathcal{V}_{D}$.

\section{State observer design}

Let $L_{i}, i=1, \ldots, 2^{l}$ be the constant gains corresponding to the observers estimating the state of the original system when $\rho(k) \in \mathcal{V}_{D}$ :

$$
\begin{aligned}
\hat{x}(k+1) & =A_{i} \hat{x}+B u+L_{i}(y(k)-\hat{y}(k)) \\
\hat{y}(k) & =C x(k)
\end{aligned}
$$

By $\left(\begin{array}{lllll}b_{1} & b_{2} & b_{3} & \ldots & b_{l}\end{array}\right)$ we denote the binary representation of the index $i$ in (4)-(5), that is each $L_{i}$ corresponds to a parameter vector value

$$
\rho^{T}=\left(\begin{array}{llll}
\tilde{\rho}_{1} & \tilde{\rho}_{2} & \ldots & \tilde{\rho}_{l}
\end{array}\right), \quad \tilde{\rho}_{j}=\left\{\begin{array}{c}
\underline{\rho}_{j} \text { if } b_{j}=0 \\
\bar{\rho}_{j} \text { if } b_{j}=1
\end{array}\right.
$$

with $j=1,2, \ldots, l$. The parameter varying gain matrix $L(\rho)$ is obtained by an interpolation of the gains $L_{i}$ :

$$
L(\rho(k))=\mu_{1}(\rho(k)) L_{1}+\ldots+\mu_{2^{l}}(\rho(k)) L_{2^{l}}
$$


The nonlinear interpolation functions $\mu_{1}(\rho), \ldots, \mu_{2^{l}}(\rho)$ are given by

$$
\begin{aligned}
& \mu_{i}(\rho(k))=\prod_{j=1}^{l} \frac{\alpha_{j} \rho_{j}(k)+\beta_{j}}{\underline{\rho}_{j}-\bar{\rho}_{j}} \\
& i \equiv\left(\begin{array}{llll}
b_{1} & b_{2} & \ldots & b_{l}
\end{array}\right)
\end{aligned}
$$

where

$\alpha_{j}=\left\{\begin{array}{ccc}1 & \text { if } & b_{j}=0 \\ -1 & \text { if } & b_{j}=1\end{array}, \quad \beta_{j}=\left\{\begin{array}{ccc}-\bar{\rho}_{j} & \text { if } & b_{j}=0 \\ \underline{\rho}_{j} & \text { if } & b_{j}=1\end{array}\right.\right.$

Moreover, these interpolation functions are characterized by

$$
\sum_{i=1}^{2^{l}} \mu_{i}(\rho)=1, \text { and } 0 \leq \mu_{i}(\rho) \leq 1, \quad i=1,2, \ldots, 2^{l}
$$

Using this choice of interpolation functions, we are also guaranteed that when the parameter values corresponds to the variation domain vertices $\left(A(\rho(k))=A_{i}\right)$, the interpolated gain observer is $\left(L(\rho(k))=L_{i}\right)$. When using the interpolated parameter varying observer (3) to estimate the state of the original LPV system, the error dynamic is given by:

$$
e(k+1)=(A(\rho(k))-L(\rho(k)) C) e(k)
$$

where $L(\rho(k))$ is given by

$$
L(\rho)=\sum_{j=1}^{2^{l}} \mu_{j}(\rho) L_{j}, \mu_{j}(\rho) \geq 0, \sum_{j=1}^{2^{l}} \mu_{j}(\rho)=1
$$

The interpolated parameter varying observer determination reduces to the computation of the constant gains $L_{j}, j=1,2, \ldots, l$ such that the polytopic uncertain system (8) is asymptotically stable. As the parameter $\rho(k)$ is time varying, the quadratic stability concept appears to be well suited. The following proposition states LMI conditions that allow, when are feasible, to get such a parameter varying observer.

Proposition 1 The error reconstruction (8) is asymptotically stable if there exist matrices $R_{j}$ and a symmetric matrix $P$ such that

$$
\left[\begin{array}{cc}
P & A_{i}^{T} P-C^{T} R_{j}^{T} \\
P A_{i}-R_{j} C & P
\end{array}\right]>\mathbf{0}
$$

for all $i=1,2, \ldots, l, j=1,2, \ldots, l$. If (10) is feasible then a parameter varying observer for the LPV system (1) is given by (3) with the interpolation based matrix gain $L(\rho(k))$ being determined by (6)-(7) and where

$$
L_{j}=P^{-1} R_{j}
$$

The error dynamics obtained using a parameter varying observer built as indicated in Proposition 1 converges to the origin asymptotically. One can also look for a faster convergence rate using the decay rate concept [3] defined, in the discrete time case, as the larget scalar $\gamma \geq 1$ such that

$$
\lim _{k \rightarrow \infty} \gamma^{k}\left\|e_{k}\right\|=0
$$

holds for all trajectories $e(k)$. The asymptotic convergence corresponds to $\gamma=1$. We can use the quadratic Lyapunov function $V(e(k))=e^{T}(k) P e(k)$ to establish a lower bound on the decay rate $\gamma$. The LTI observer gains are then designed using the following proposition.

Proposition 2 Assume that the following convex optimisation problem

$$
\begin{array}{clc}
\text { Min } & \beta & \\
\text { s.t } & {\left[\begin{array}{cc}
-\beta P & A_{i}^{T} P-C^{T} R_{j}^{T} \\
P A_{i}-R_{j} C & P
\end{array}\right]>\mathbf{0},} \\
& 0<\beta<1 &
\end{array}
$$

for $i=1,2, \ldots, l$ and $j=1,2, \ldots, l$ admits a solution $\beta=\beta_{*}$ with the correponding matrices $P_{*}=P_{*}^{T}$ and $R_{* j}$, then the interpolated parameter varying observer obtained with $L_{j *}=P_{*}^{-1} R_{* j}$ leads to an error convergence to the origin with a decay rate at least equal to $\beta_{*}^{-\frac{1}{2}}$.

In the case of slow parameter variations such that the system can be considered as time invariant over time intervals, a pole placement constraint can be imposed to improve the convergence of the observation error.

\section{Conclusion}

An interpolation based method has been proposed to design a parameter varying observer. It is based on the resolution of LMI conditions similar to the ones arising in robust control techniques. Even if the methods based on such a concept are conservative, the fairly large contributions in this domain show the interest of the obtained results.

\section{References}

[1] D. J. Leith and W. E. Leithead, "Survey of gain scheduling analysis and design", To appear in International Journal of Control 2000.

[2] D. J. Stiwell and W. J. Rugh, "Interpolation of observer state feedback controllers for gain scheduling", IEEE Trans. on Automatic control, vol. 44, pp. 12251229, 1999.

[3] S. Boyd, L. El Ghaoui, E. Feron, and V. Balakrishnan, Linear Matrix Inequality in Systems and Control Theory, Studies in Applied Mathematics, 1994. 